\title{
Strategies for Self-Fulfillment of Ambitious Young People
}

\author{
Oksana Barsukova ${ }^{1, *}$,Elena Scherbina $^{1}$, Olesya Shestopalova $^{1}$, and Daria Demicheva ${ }^{1}$ \\ ${ }^{1}$ Southern Federal University, B. Sadovay str., 105, Rostov-on-Don, Russia
}

\begin{abstract}
The article presents the results of a comparative analysis of self-fulfillment strategies in ambitious and unambitious young people. Ambition is understood by us as the desire of a person to become a significant person and to be recognized by other people for their achievements. Self- fulfillment is a person's empowerment of himself, his personality, his value, this desire for high appreciation and self-esteem, and the behavior corresponding to this desire. Self- fulfillment can be implemented in one of three strategies - constructive, aggressive, or in the rejection of self- fulfillment. We assumed that there would be differences in the representation of self-fulfillment on strategies among ambitious and unambitious young people. The study involved 94 young people aged 1822 years. The majority of young people consider themselves ambitious or rather ambitious people (70.21\%). Less than a third of young people consider themselves to be unambitious or rather unambitious people $(29.79 \%)$. In ambitious young people, two strategies of self- fulfillment were identified - constructive self-affirmation $(60.60 \%)$ and rejection of self-affirmation $(39.39 \%)$. Three strategies were identified among ambitious young people - refusal of self- fulfillment $(42.86 \%)$, constructive self- fulfillment $(42.86 \%)$ and aggressive self- fulfillment $(14.28 \%)$. There were no statistically significant differences in the representation of constructive self- fulfillment and rejection of selffulfillment in ambitious and unambitious young people. The only difference is that aggressive self- fulfillment is presented unambitious in unholy young people and is not present in ambitious young people.
\end{abstract}

\section{Introduction}

The world in which a person lives is complexly organized and consists of different realities (or worlds). This is the inner and outer world of a person. Inner world of the person includes thoughts, feelings, believes, dreams, etc. If we consider the external world of a person in more details, it includes the social environment, nature, the world of material objects, etc. In addition to the" traditional " realities in which a person lives for more than one century, virtual reality, the digital world, had entered the world of modern man. The new virtual world expands the sphere of life activities of a modern person, provides opportunities for the realization of their needs and desires, and in particular, those related to

\footnotetext{
*Corresponding author: knesinka@mail.ru
} 
the social life of a person and his interaction with other people. A large number of modern psychological studies are devoted to the study of human activity in virtual reality. This is the development of a method for studying human behavior in virtual reality [1]. This is a study of the role of technological artefacts in the promotion of prosocial behavior [2]. Another example of such kind of research is the study of gratitude in virtual social interaction [3].The formation of social capital in an online social community [4] is also studied. In addition, an analysis of theoretical sources devoted to the study of virtual reality is provided, for example, meta-scientific analysis of articles out virtual reality [5]. The desire for self-affirmation and ambition are the motives that direct the social activity of the individual in various spheres of human life, including virtual reality. Social activity is a purposeful activity of a person in a society, a change in society, namely, changing the circumstances of people's lives and changing their lives in order to get a certain benefit for themselves and/or other people. Social activity is determined by various factors, including personal characteristics of a person. Among the diversity of all personal characteristics, special attention, in our opinion, belongs to the motivational sphere. In particular, the focus of our attention is on such motives as the desire for self-affirmation and ambition [6]

Ambition is considered by us as the desire of a person to become a recognized, significant person for other people [6;7]. Ambition is a stable characteristic of the individual, it does not depend on the gender and age of the person. Ambition affects various character traits, and in particular, increases dominance, courage, achievement motivation, self-actualization, responsibility, selfishness, careerism, etc. [7]. In the studies of Ashley Bell Jones and colleagues, the relationship between ambition and social boldness, liveliness (extra-version), diligence and prudence (conscientiousness) [8] was revealed. We also recall the research devoted to ambition as one of the characteristics of behavior and personality of type A.

It can be argued that ambition is associated with a wide range of personal characteristics of a person. At the first glance, ambition combines incongruous characteristics. Ambition manifests itself in different areas of a person's social life. However, there is still a lack of clarity about the definite, stable connections of ambition with other personality characteristics and character traits $[6 ; 7 ; 8]$.

A number of modern studies in psychology, sociology, economics, and other social sciences are devoted to the study of ambition in the context of human social activity. In our previous study, we found similarities in the ambition of representatives of different generations $-\mathrm{X}$ and $\mathrm{Y}$ generations [9]. Junyi Chai considers ambition as one of three state variables (ambition, retaliation, aspiration)-the model delivers a new measure of individual well-being under both social and historical contexts [10]. Ambition is studied as a factor that inhibit or foster accumulation of wealth [11]. We study the political ambitions - the political ambitions of students [12], the gender aspect of political ambition [13]. The factors influencing future academic ambition [14], the relationship between ambitions and future social status and earnings [15] and etc. are studied.

Ambition directs the activity of a person to achieve such goals that can only be achieved in the social sphere of human life-this is a high social status, social success, power, professional growth and career, etc. Self-fulfillment is a person's empowerment of himself, his personality, and his meaning. This is the desire for high esteem and self-esteem and the behavior corresponding to this desire. This is the empowerment of oneself as a person in the world, the affirmation of one's own "Self " in relation to the "Not Self ".

Self- fulfillment is possible only in the process of communication and interaction with other people, in the social space of the individual. Thus, the two main goals that a person strives to achieve in the process of self- fulfillment can be called high self-esteem and social status. Self- fulfillment can be achieved at the expense of real or declared 
achievements. In Russian psychology, it is customary to distinguish three strategies of selfaffirmation, in particular, the research of E. P. Nikitin and N. E. Kharlamenkova [16]:

"Rejection of self- fulfillment " (uncertain strategy, self-suppression, self-denial). This strategy manifests itself in the form of depression, autoaggression, refusal of self-realization and self-development, in a low level of achievement, self-humiliation, self-denial, passiveindifferent behavior, and loss of the meaning of life. A person does not believe in himself, his own strength, seeks to establish symbiotic connections, to be attached to others.

"Constructive self- fulfillment ". This strategy manifests itself in the form of assistance to others, mutual assistance and mutual support, productive activity, thanks to which a person can experience a sense of self-worth and significance. This strategy is socially approved and supported by the positive attitude of others.

"Aggressive self- fulfillment " (dominance, destructive self-assertion). This strategy manifests itself in the form of negativism, denial of the personal value and significance of the other, suppression of the other's personality. In relationships with others, such a person demonstrates himself. A person with such a strategy in relation to other people is guided by the principle of "fear means respect". Such behavior, as a rule, is accompanied by aggressive manifestations, which can also cause a person to feel satisfied.

It is obvious that other people who are targeted by aggression have a negative opinion of such a person. A large number of modern studies have been devoted to the factors that affect self-affirmation. For example, a study by Simon A. Moss and Samuel G. Wilson examines the effects of positive and negative emotions on self-affirmation [17]. A number of studies have examined self-affirmation in the professional sphere. This is, for example, a cross-country study of psychological empowerment as mediator of the positive association between structural empowerment and work engagement [18], a study of personnel empowerment of employee [19]. In our opinion, ambition is one of the motives that determine the self- fulfillment of the individual in society. It is ambition that will set the stage for self- fulfillment.

\section{Materials and methods}

In our study, we assumed that there would be differences in the representation of selffulfillment strategies in ambitious and unambitious young people. Namely, ambitious young people will have two strategies - constructive and aggressive self- fulfillment compared to unambitious young people. The study was conducted using two methods "Diagnostics of the strategies of self- fulfillment of the individual" (N.E. Kharlamenkova, E.P. Nikitin) and "Ambition" (O.V. Barsukova). For mathematical and statistical processing of the obtained data, the Fischer $\varphi$-criterion was used. The study involved 94 people aged 18-25 years.

\section{Results}


The study of the self-fulfillment of the ambition of young people allowed us to obtain the following results and to distinguish two groups of young people-ambitious and unambitious.

The first group is ambitious young people. The majority of young people $(70.21 \%)$ consider themselves ambitious people or rather ambitious than unambitious people. These young people plan to realize their ambition, first of all, in the professional sphere, they want to achieve success and recognition. But they also associate the realization of their ambition with the creation of a family.

The second group is the unambitious young people. About a third of young people $(29.79 \%)$ consider themselves to unambitious people or rather unambitious than ambitious people. These young people associate the realization of their ambition with education and profession. In a further study, self-affirmation strategies were identified in young people of both groups:

The first group. In ambitious young people, two out of three strategies of selffulfillment were identified: In most of them, the strategy of "constructive self- fulfillment" prevails $(60.60 \%)$. At the same time, a significant part of them the strategy of "refusal of self- fulfillment " was revealed (39.39\%). A large percentage of ambitious young people who refuse to assert themselves contradicts the characteristics of an ambitious person. It was also unexpected that the group of ambitious young people did not present a strategy of aggressive self- fulfillment.

The second group. Three strategies of self-affirmation have been identified in the unambitious young. In this group, two self- fulfillment strategies are equally represented "rejection of self- fulfillment " and "constructive self- fulfillment " (42.86\% of each strategy). Also in this group of young people, the strategy of "aggressive self- fulfillment " was revealed (14.28\%).

Table 1. Strategies for self-fulfillment of ambitious and unambitious young people.

\begin{tabular}{|l|l|l|l|}
\hline $\begin{array}{l}\text { Self- fulfillment } \\
\text { strategies }\end{array}$ & Ambitious & unambitious & $\begin{array}{l}\text { Significance } \\
\text { differences }\end{array}$ \\
\hline $\begin{array}{l}\text { Rejection of self- } \\
\text { fulfillment (self-denial) }\end{array}$ & $39.39 \%$ & $42.86 \%$ & $\varphi=0.223, \mathrm{p}=0.05$ \\
\hline $\begin{array}{l}\text { Constructive self- } \\
\text { fulfillment }\end{array}$ & $60.60 \%$ & $42.86 \%$ & $\varphi=1.116, \mathrm{p}=0.05$ \\
\hline $\begin{array}{l}\text { Aggressive self- } \\
\text { fulfillment (dominance) }\end{array}$ & - & $14.28 \%$ & - \\
\hline
\end{tabular}

As can be seen from the results presented in Table 1:

The strategy of "Rejection of self-fulfillment (self-denial)" has a slight advantage in young people who consider themselves to be unambitious $(42.86 \%)$ compared to young people who consider themselves to be ambitious (39.39\%). Obviously, these differences are not significant $(\varphi=0.223, \mathrm{p}=0.05)$. This strategy is presented in a significant number of young people, independent of what they consider themselves ambitious or unambitious people.

The strategy of "constructive self-fulfillment" prevails among young people who consider themselves ambitious (60.60\%) compared to young people who do not consider themselves ambitious $(42.86 \%)$. However, these differences are not significant $(\varphi=1.116$, $\mathrm{p}=0.05)$. $\mathrm{T}$

he strategy of "aggressive self-fulfillment (dominance)" is presented only in dishonest young people $(14.28 \%)$.

\section{Discussion}


The results partially confirmed the assumption that there is a difference in the representation of self-fulfillment strategies in ambitious and unambitious young people. At the same time, our assumption that ambitious young people will express two strategiesconstructive and aggressive self-fulfillment - in comparison with unambitious young people was not confirmed.

The predominance of the strategy of "constructive self-fulfillment" among ambitious young people suggests that their constructive orientation of their social activity, namely, the choice of not only personally significant, but socially approved goals and means of achieving these goals.

The analysis of the studies of ambition allowed us to assume that along with the strategy of "constructive self-fulfillment", ambitious young people will also have the strategy of "aggressive self-fulfillment". As shown in a number of studies, ambition is associated with dominance, social courage, and competitiveness as qualities that contribute to a social career $[7 ; 8]$. However, the strategy of "aggressive self-fulfillment" was not identified in these young people. This result makes us think and reconsider the results of our and other studies on the relationship between aggressiveness and ambition. It is obvious that this direction of our research will be continued.

Further theoretical and empirical research is also needed on the data on the high percentage of ambitious young people who refuse to assert themselves. Such a passive attitude contradicts the characteristics of an ambitious person in psychological sources.

\section{Conclusions}

Summing up the results of our research, we note the following:

- Most young people consider themselves ambitious people. Less than a third of young people consider themselves to be unambitious people.

- Ambitious young people have two strategies for self-fulfillment - constructive selffulfillment (predominates) and rejection of self- fulfillment.

- Unambitious young people have three strategies for self-fulfillment - constructive selffulfillment and rejection of self- fulfillment (both strategies are presented equally) and aggressive self- fulfillment (presented minimally).

- The comparative analysis of self- fulfillment strategies did not confirm or only partially confirmed our assumption that there will be differences in self- fulfillment strategies in ambitious and unambitious young people.

- There were no statistically significant differences in the representation of the strategies of "constructive self- fulfillment" and "rejection of self- fulfillment" in ambitious and unambitious young people.

- The strategy of "aggressive self- fulfillment" was revealed only in unambitious young people.

Our research on the self-fulfillment strategies of ambitious young people will continue. On the one hand, we plan to analyze theoretical sources on the issues of ambition and the personality characteristics that are associated with it. On the other hand, we are going to plan to pay attention to the representation and expression of two self- fulfillment strategies "aggressive self- fulfillment" and "rejection of self- fulfillment".

\section{References}

1. H.E. Yaremych, S. Persky, Tracing physical behavior in virtual reality: A narrative review of applications to social psychology. Journal of Experimental Social Psychology, 85 (2019) https://doi.org/10.1016/j.jesp.2019.103845 
2. R. Oliveira, P. Arriaga, F.P. Santos, S. Mascarenhas, A. Paiva, Towards prosocial design: A scoping review of the use of robots and virtual agents to trigger prosocial behavior. Computers in Human Behavior, $114 \quad$ (2021) https://doi.org/10.1016/j.chb.2020.106547

3. J. Collange, J. Guegan, Using virtual reality to induce gratitude through virtual social interaction. Computers in Human Behavior, 113 (2020) https://doi.org/10.1016/j.chb.2020.106473

4. S. Sanz-Blas, D. Buzova, P. Perez-Ruiz, Building relational worth in an online social community through virtual structural embeddedness and relational embeddedness, Technological Forecasting and Social Change, $162 \quad$ (2021) https://doi.org/10.1016/j.techfore.2020.120350

5. M. Lanier, T.F. Waddell, M. Elson, D.J. Tamul, J.D. Ivory, A. Przybylski, Virtual reality check: Statistical power, reported results, and the validity of research on the psychology of virtual reality and immersive environments. Computers in Human Behavior, 100, 70-78 (2019) https://doi.org/10.1016/j.chb.2019.06.015

6. O. Barsukova, N. Mozgovaya, L. Kosikova, Ambition and personal space as a phenomena of social interaction. Culture and Education: Social Transformations and Multicultural Communication: Proceedings of the Middle-Term Conference RC04 Sociology of Education International Sociological Association (ISA), 673 p. (Institute of Foreign Languages RUDN University, Moscow) (2019). DOI: 10.22363 / 096692019-306-312

7. E. Ilyin, The psychology of envy, hostility, vanity. Piter, Saint-Petersburg, ISBN 9785-496-00712-2 (2014)

8. A. B. Jones, R. A. Sherman, R. T. Hogan, Where is ambition in factor model of personality? Personality and Individual Differences, 106(1), 26-31 (2017) doi.org/10.1016/j.paid.2016.09.057

9. O. Barsukova, N. Mozgovaya, E. Scherbina, L. Kosikova, N. Lomova, Ambition of young people - representatives of $Y$ and $Z$ generations. E3S Web Conf. Volume 210, 2020 Innovative Technologies in Science and Education (ITSE-2020), 20005, 6, Section Psychology of Sustainability and Human (2020) https://doi.org/10.1051/e3sconf/202021020005

10. J. Chai, A model of ambition, aspiration and happiness. European Journal of Operation Research, 288(2), 692-702 (2021) doi.org/10.1016/j.ejor.2020.06.009.

11. F. Tournemaine, C. Tsoukis, Gain versus pain from status and ambition: Effects on growth and inequality. The Journal of Socio-Economics, 39(2), 286-294 (2010) https://doi.org/10.1016/j.socec.2009.10.007

12. J. Blais, S. Pruysers, The power of the dark side: personality, dark triad, and political ambition. Personality and Individual Differences, 113, 167-172 (2017) doi.org/10.1016/j.paid.2017.03.029

13. J. Pate, R. Fox, Getting past the gender gap in political ambition. Journal of Economical Behavior and Organization, 156, 166-183 (2018) https://doi.org/10.1016/j.jebo.2018.10.002

14. K.A. Machell, D.V. Blalock, T.B. Kashdan, M. Yuen, Academic achievement at the cost of ambition: The mixed results of a supportive, interactive environment on socially anxious teenagers. Personality and Individual differences, 89, 166-171 (2016) https://doi.org/10.1016/j.paid.2015.10.018 
15. J.S. Ashby, I. Schoon, Career success: The role of teenage career aspirations, ambition value and gender in predicting adult social status and earnings. Journal of Vocational Behavior, 77(3), 350-360 (2010) https://doi.org/10.1016/j.jvb.2010.06.006

16. E.P. Nikitin, N.E. Harlamenkova, The phenomenon of human self-empowerment. Aletheia (Saint-Petersburg, 2000)

17. S. A. Moss, S. G. Wilson, The positive emotions that facilitate the fulfillment of needs may be not positive emotions at all: The role of ambivalence. Explore, 11(1), 40-50 (2015) https://doi.org/10.1016/j.explore.2014.10.006

18. M. A. Amor, D. Xanthopoulou, N. Calvo, J.P. Abeal Vazquez, Structural empowerment, psychological empowerment, and work engagement: Across-country study, European Management Journal (2021) https://doi.org/10.1016/j.emj.2021.01.005

19. C. Bektas, N. Sohrabifard, Terms of Organization Psychology, Personnel Empowerment and Team Working: A Case Study. Procedia - Social and Behavioral Sciences, 82, 886-891 (2013) https://doi.org/10.1016/j.sbspro.2013.06.366 